\title{
Swimming patterns of larval Strongylocentrotus droebachiensis in turbulence in the laboratory
}

\author{
Amy Roy*, Anna Metaxas, Tetjana Ross \\ Department of Oceanography, Dalhousie University, Halifax, Nova Scotia B3H 4R2, Canada
}

\begin{abstract}
We exposed 4-arm plutei of the sea urchin Strongylocentrotus droebachiensis to 2 levels of turbulent dissipation rates $\left(\varepsilon: 9 \times 10^{-9}\right.$ or $\left.4 \times 10^{-7} \mathrm{~W} \mathrm{~kg}^{-1}\right)$ in the laboratory, generated by using an oscillating metal grid. We compared direction of displacement and vertical velocities of larvae in turbulence with those of larvae in no flow and of passive particles in turbulence, for 2 different larval populations and over 2 trials. In turbulence, larval and passive particle movements were measured using particle image velocimetry, whereas larvae in no flow were filmed and their movements tracked digitally. Larvae in no flow and low turbulence tended to move towards the water surface, and this behaviour became more pronounced over time, suggesting that larvae became habituated to the turbulent flow. In high turbulence, larvae were unable to swim towards the surface of the water column and were consequently transported in secondary flows like passive particles. These levels of turbulence are likely to be encountered by larvae in near-shore coastal embayments or the surface layer of the continental shelf and will affect larval dispersal away from, or towards, parental habitats.
\end{abstract}

KEY WORDS: Turbulence $\cdot$ Larvae $\cdot$ Sea urchin $\cdot$ Swimming patterns $\cdot$ Turbulent dissipation rate Weak swimmer $\cdot$ Benthic marine invertebrates $\cdot$ Angle of displacement $\cdot$ Batch effects

\section{INTRODUCTION}

Larval dispersal and retention of marine benthic invertebrates regulates population expansion and maintenance (Strathmann et al. 2002). Retained larvae settle and recruit near parental populations, forming the next cohort of that population, while larvae that disperse promote genetic exchange with distant populations or, if they settle in previously unoccupied habitats, expand the range of the species. Larvae of a variety of species have been shown to respond to a number of cues both biological, such as food, predators and conspecifics (Young 1995, Metaxas \& Young 1998, Metaxas \& Burdett-Coutts 2006, Roy et al. 2012), as well as physical, such as light, temperature, salinity and gravity, that they may encounter while in the water column (Welch et al. 1999, Metaxas 2001, Welch \& Forward 2001). Larval distribution can also be altered by the flow regime
(Pearce et al. 1998). Shear forces, caused by the presence of a salt wedge or simple laminar flow, have been shown to prevent the formation of aggregations of echinoderm larvae at the water surface. Instead, larvae were reoriented and aggregated below the halocline or became more evenly distributed at depth in stratified water columns.

Coastal flow regimes are often turbulent, and the dissipation rate of turbulent kinetic energy $(\varepsilon)$ can range from $10^{-14}$ to $10^{-4} \mathrm{~W} \mathrm{~kg}^{-1}$ (Lueck et al. 1983, Haury et al. 1990, Fuchs et al. 2010). During short wind events $(<2 d), \varepsilon$ at a particular depth has been shown to vary over 2 orders of magnitude, before returning to baseline values (Incze et al. 2001). Typically, the surf zone and tidal channels have the highest levels of turbulence ( $\varepsilon: 10^{-5}$ to $10^{-1}$ and $10^{-6}$ to $10^{-4}$ W kg ${ }^{-1}$ respectively; George et al. 1994, Gross \& Nowell 1985), while the mixed layer on the continental shelf has intermediate values $\left(10^{-9}\right.$ to $\left.10^{-6} \mathrm{~W} \mathrm{~kg}^{-1}\right)$ 
and the open ocean mixed layer the lowest $\left(10^{-11}\right.$ to $10^{-6} \mathrm{~W} \mathrm{~kg}^{-1}$; Dillon \& Caldwell 1980, Oakey \& Elliott 1982). Near-shore subtidal habitats typically exhibit $\varepsilon$ of $10^{-9}$ to $10^{-5} \mathrm{~W} \mathrm{~kg}^{-1}$ in calm conditions, and up to $10^{-4} \mathrm{~W} \mathrm{~kg}^{-1}$ under breaking waves (George et al. 1994, Goodman \& Wang 2009). Larvae that are released in subtidal habitats, such as bivalves, gastropods and echinoderms, will likely encounter turbulence in the mixed layer of the continental shelf, near-shore subtidal habitats and possibly the surf zone or tidal channels.

Only a few studies have examined the effects of turbulent flow on the swimming behaviour of weakly swimming larvae, such as echinoderms, bivalves and gastropods (swimming velocities $\leq 1 \mathrm{~mm} \mathrm{~s}^{-1}$; Chia et al. 1984). In a laboratory mesocosm, competent scallop larvae Placopecten magellanicus displayed similar vertical distributions at different levels of turbulence $\left(10^{-11}<\varepsilon<10^{-7} \mathrm{~W} \mathrm{~kg}^{-1}\right.$; Pearce et al. 1998). However, larval growth to competence and settlement success rate were significantly reduced at the highest levels (Pearce et al. 1998). In contrast, settlement success of mussel larvae Mytilus edulis was enhanced with increased turbulence, up to a threshold level ( $\varepsilon$ not provided; Pernet et al. 2003). Larvae of the gastropod Ilyanassa obsoleta, which settles on intertidal mudflats, withdrew their velum and sank when exposed to turbulence, suggesting that turbulence may act as a settlement cue (Fuchs et al. 2010). The likelihood of this behaviour increased with increasing turbulence above a threshold $\varepsilon$ of $10^{-6} \mathrm{~W}$ $\mathrm{kg}^{-1}$ (Fuchs et al. 2004). In contrast, the gastropods Crepidula spp. and Anachis spp. responded to turbulence by swimming upwards, and sank by retracting their velum in calm water (Fuchs et al. 2010).

Behavioural responses to turbulence have also been measured for stronger-swimming meroplankton such as crab megalope (swimming velocity of $\sim 1$ to $10 \mathrm{~cm} \mathrm{~s}^{-1}$; Luckenbach \& Orth 1992), copepods (swimming velocities of $\sim 1$ to $10 \mathrm{~mm} \mathrm{~s}^{-1}$; Yamazaki \& Squires 1996) and fish larvae (swimming velocities of 1 to $10 \mathrm{~s} \mathrm{~cm} \mathrm{~s}^{-1}$; Batty 1984). Crab megalope use changes in $\varepsilon$ as a swimming cue, possibly promoting dispersal to suitable settlement habitats (Welch et al. 1999, Welch \& Forward 2001). Copepods increase the number of escape reactions in the presence of turbulence, but eventually become habituated (Costello et al. 1990, Saiz \& Alcaraz 1992, Seuront et al. 2004). In addition, growth of nauplii accelerates in the presence of turbulence, but later-stage growth and adult size are reduced (Saiz \& Alcaraz 1991). In the field, copepods appear to avoid turbulence levels above a threshold $\varepsilon$ of $10^{-7}$ to $10^{-6} \mathrm{~W} \mathrm{~kg}^{-1}$, by descending to deeper depths (Maar et al. 2006). It has been speculated that the avoidance of wind-driven surface turbulence by copepods may promote the retention of holoplankton in upwelling zones, and prevent advection away from other preferred habitats (Pringle 2007).

In the present study, we examined the ability of weakly swimming larvae of the sea urchin Strongylocentrotus droebachiensis (Müeller) to maintain their swimming patterns in turbulence. Unlike previous studies, which have focused on competent larvae, we used 4-arm plutei of $S$. droebachiensis to understand how turbulence may influence larval displacement during their early dispersive life stage. In the laboratory, we manipulated the frequency of oscillation of a metal grid to create different levels of turbulence to determine: (1) whether larval swimming patterns of $S$. droebachiensis are affected by turbulence, and (2) at what threshold of turbulence larvae are displaced passively. To achieve these 2 goals, we compared the movement patterns (i.e. swimming plus turbulent motion) of $S$. droebachiensis larvae in turbulence with those of larvae in no flow (i.e. only swimming) and to passive particles in turbulence (only turbulent motion). We predicted that larvae of $S$. droebachiensis will not be able to maintain their swimming pattern above a $\varepsilon$ of $\sim 10^{-8} \mathrm{~W} \mathrm{~kg}^{-1}$, a value shown to affect other similarly weakly swimming invertebrate larvae. We also examined changes in larval response to turbulence over time to assess whether habituation occurs on short timescales (10s of minutes). Given the prevalence of turbulence in their natural habitat, understanding how larvae respond to this physical cue during their dispersive phase is necessary to be able to predict their transport.

\section{MATERIALS AND METHODS}

\section{Larval spawning and rearing}

Adult Strongylocentrotus droebachiensis were collected from the shallow subtidal zone at Duncan's Cove, Nova Scotia, Canada, in March 2011, transferred to Dalhousie University, kept in flow-through tanks of the Aquatron running seawater facility at ambient seawater temperature $\left(5\right.$ to $\left.10^{\circ} \mathrm{C}\right)$ and fed the kelps Saccharina longicruris and Laminaria digitata ad libitum.

To induce gamete release, adult Strongylocentrotus droebachiensis were injected with 2 to $4 \mathrm{ml}$ of $0.55 \mathrm{M} \mathrm{KCl}$ through the peristomial membrane. Eggs 
were collected in $100 \mathrm{ml}$ of $0.45 \mu \mathrm{m}$ filtered seawater, while sperm was dry-collected and kept on ice until used for fertilisation. After we ensured gamete viability, eggs and sperm were mixed in $3.5 \mathrm{l}$ of $0.45 \mu \mathrm{m}$ filtered seawater at 34 and 9 to $11^{\circ} \mathrm{C}$, and gently stirred. Fertilisation success, as indicated by an elevated perivitelline membrane, ranged between 94 and $100 \%(\mathrm{n}=50)$.

Larvae were reared in $4 \mathrm{l}$ glass jars, containing $3.5 \mathrm{l}$ of $0.45 \mu \mathrm{m}$ filtered seawater with a salinity of 34 , and gently stirred with slowly rotating paddles at a density of $\sim 10 \mathrm{in} . \mathrm{ml}^{-1}$ (due to the large number of larvae required). Larval size (and consequent swimming ability) at this population density was not significantly different from that for larvae raised at 3 ind. $\mathrm{ml}^{-1}$ (mean length $\pm \mathrm{SD}, \mathrm{n}=20$ ): $0.62 \pm 0.07 \mathrm{~mm}$; 10 ind. $\mathrm{ml}^{-1}: 0.56 \pm 0.04 \mathrm{~mm}$ (A. Roy unpubl. data). A mixture of larvae from 3 to 4 parental pairs contributed equally to the population within each jar and replicate jars contained the same combination of parental pairs. As multiple jars were used for each trial, possible jar effects were subsumed. The larvae were maintained in a temperature-controlled room with a 12:12 h light:dark cycle, at $10 \pm 1^{\circ} \mathrm{C}$. The water in each jar was changed every other day and a mixture of the phytoplankton Isochrysis galbana and Chaetoceros muelleri was added at a total concentration of $\sim 5000$ cells ml ${ }^{-1}$.

\section{Response to turbulence}

\section{Experimental tank}

Turbulence was generated in a clear Lexan $275 \mathrm{l}$ tank $(68 \times 61 \times 75 \mathrm{~cm}, \mathrm{~L} \times \mathrm{W} \times \mathrm{H})$ with an oscillating grid, similar to Hopfinger \& Toly (1976). The grid was open-ended and had a mesh size of $8 \mathrm{~cm}$, yielding square openings of $7 \times 7 \mathrm{~cm}$ (Fig. 1). A rotary motor was attached to the grid via a driving mechanism, which translated the circular motions to a reciprocating oscillation with a stroke of $9.2 \mathrm{~cm}$. The grid oscillated at 2 different frequencies: $0.13 \mathrm{~Hz}$ or $0.56 \mathrm{~Hz}$ (low and high turbulence, respectively). These oscillation frequencies were selected to generate turbulence levels with horizontal root mean square (RMS) turbulent velocities $\left(u^{\prime}\right)$ that were either slower, or above the threshold vertical swimming velocities $\left(\sim 0.2 \mathrm{~mm} \mathrm{~s}^{-1}\right)$ of 4-arm larvae of Strongylocentrotus droebachiensis (based on the empirical relationships in Hopfinger \& Toly 1976). The tank was filled with $275 \mathrm{l}$ of $100 \mu \mathrm{m}$ filtered seawater at 34 psu and $10.5 \pm$ $1.0^{\circ} \mathrm{C}$ (water depth: $66.5 \mathrm{~cm}$ ).

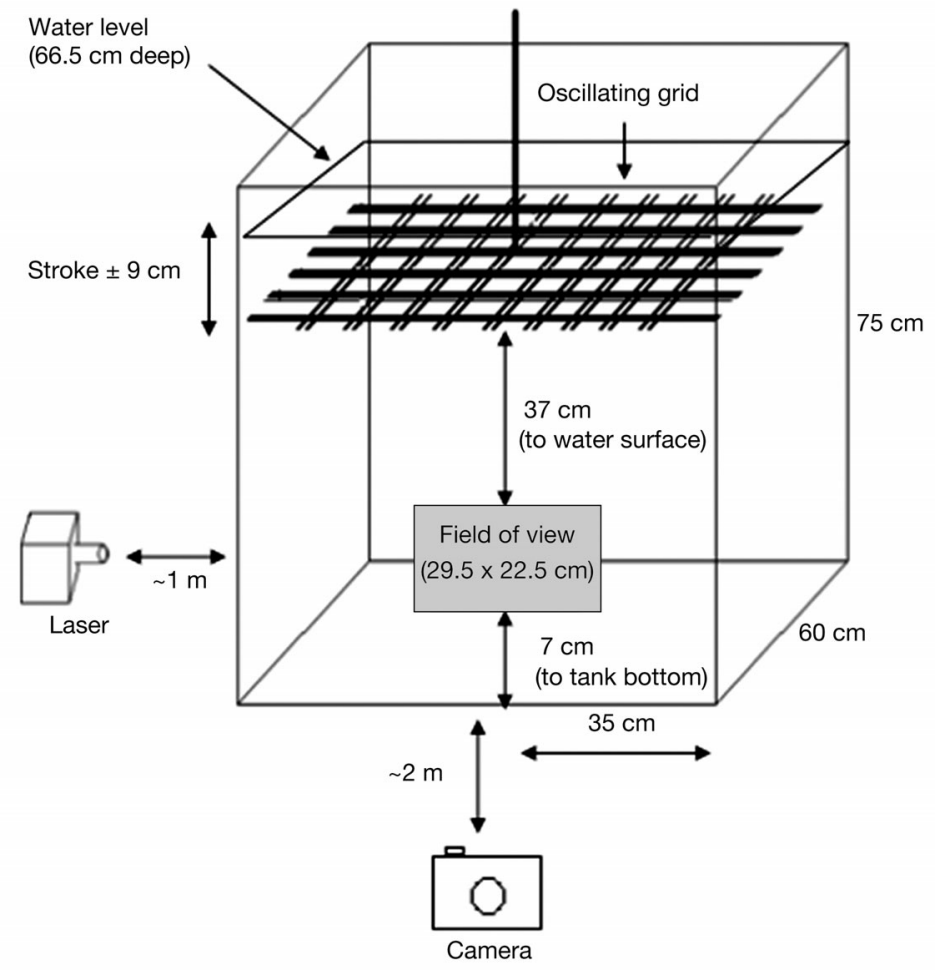

Fig. 1. Schematic drawing of experimental set-up (not to scale)

A NewWave Solo particle image velocimetry (PIV) $120 \mathrm{Nd}$ :YAG $532 \mathrm{~nm}$ laser was placed $\sim 1 \mathrm{~m}$ from the edge of the tank and was aligned halfway along the width of the tank, with the laser head aimed at a height of $15 \mathrm{~cm}$ above the bottom of the tank. A Hamamatsu C8484-05CP digital charge-coupled device (CCD) camera with a Nikon AF Micro Nikkor $60 \mathrm{~mm}$ macro lens, which yielded a resolution of $60 \mu \mathrm{m}$ (allowing the image capture of individual larvae), was placed perpendicular to the laser beam, halfway along the length of the tank (Fig. 1). The CCD camera was focused to $15 \mathrm{~cm}$ above the bottom of the tank and was within the laser's light sheet. The laser light sheet was $\sim 8 \mathrm{~mm}$ deep, and the camera captured an image area of $1344 \times 1024$ pixels (W $\times$ H). Using Dantec Dynamics' FlowManager software, the laser and camera were synchronised to capture 1000 image pairs, with $80 \mathrm{~ms}$ between the first and second image in a pair, and $1 \mathrm{~s}$ between image pairs.

The image area captured by the CCD camera was centred along the length and width of the tank, with the top of the image area $\sim 37.1 \mathrm{~cm}$ below the water surface and $7 \mathrm{~cm}$ from the bottom of the tank (Fig. 1). This image capture location was chosen to maximise the distance away from both the oscillating grid and the bottom of the tank, minimising edge effects and thus maximising isotropy in the turbulence. Based on 
Hopfinger \& Toly (1976), in this area of the tank, the mean turbulent velocity scale at the top of the image capture area is $1.7 \times$ that at the bottom, and thus the turbulence is not completely homogeneous and isotropic but a reasonable approximation of it.

\section{Experimental procedure}

Polyamid passive particles $50 \mu \mathrm{m}$ in spherical diameter that were approximately neutrally buoyant were added into the Lexan tank at a density of $\sim 3$ particles $\mathrm{ml}^{-1}\left(8.25 \times 10^{5}\right.$ particles total $)$ and stirred to ensure a homogeneous distribution. After being stirred, the grid was started at the low- or high-frequency setting (depending on the desired level of turbulence) and was run for $30 \mathrm{~min}$ prior to data collection to allow the turbulence to fully develop, when 1000 image pairs were collected (the 1st trial within a replicate). The tank was then gently stirred (with the grid still oscillating), and the image collection for the 2nd trial commenced after $10 \mathrm{~min}$. The tank was stirred between trials for both the neutrally buoyant passive particles and the larvae to maintain a consistent method across particle type and, in the case of the larvae, to homogenously redistribute the larvae prior to commencing the next trial. At each turbulence level, 3 trials of 1000 image pairs were collected. To ensure both turbulence settings were consistently measured on different occasions, 1 additional trial at the lowturbulence setting with $1 \mathrm{~s}$ between image pairs and 4 additional trials at the high-turbulence setting were run with $0.5 \mathrm{~s}$ between image pairs.

To measure the swimming patterns of 4 -arm $(6 \mathrm{~d}$ old) plutei of Strongylocentrotus droebachiensis, a similar experimental procedure was employed. Larvae were gently siphoned into the tank at a density of 1 to 3 ind. $\mathrm{ml}^{-1}$ (2.75 to $8.25 \times 10^{5}$ larvae total per trial), and stirred. The grid was turned on and a 30 min acclimation period followed. At each turbulence level, we used 2 batches of larvae, and each batch included larvae from a different combination of 3 to 4 parental pairs. Although larvae from each batch (i.e. parental pair combination) were used for both turbulence levels (in an orthogonal design), subsamples of individual larvae from a batch were only exposed to a single turbulence level and then discarded. To examine whether habituation to a particular level of turbulence occurred, larvae were exposed to 2 sequential trials at each turbulence level for each batch. A previous study has indicated that there is no effect of the laser beam on larval behaviour (Roy et al. 2012).

\section{Behaviour in no flow}

To measure the swimming pattern of Strongylocentrotus droebachiensis in no flow, we filmed 4-arm plutei in $3 \mathrm{l}$ column tanks filled with $10^{\circ} \mathrm{C}$ water for 20 min at a larval density of $\sim 0.1$ ind. $\mathrm{ml}^{-1}$. This lower larval density did not act as a confounding factor, as population density affects larval behaviour at densities of $\sim 10$ ind. $\mathrm{ml}^{-1}$ (Roy et al. 2012). Two still images were extracted every $3 \mathrm{~min}$, spaced $2.5 \mathrm{~s}$ apart (similar temporal scale to data collected using PIV to allow comparisons), and the displacement of each larva in the images was tracked ( $\mathrm{n}=241$ larvae) and the Cartesian coordinates recorded. For detailed methods, see Roy et al. (2012).

\section{Data analysis}

\section{Generating vector maps}

We used vector maps to measure the displacement of particles and larvae at each level of turbulence from the collected images. Because the displacement of individual particles and larvae was too small $(<1$ pixel) to be observed between the 2 images in a collected image pair, the first image of an image pair was compared to the first image of the subsequent image pair, increasing the time interval between images to $1 \mathrm{~s}$ to allow for a measurable displacement. To achieve this, the first image of each image pair was extracted from FlowManager in a file format and imported into PIVlab v. 1.13, a graphical user interface (GUI) software, used in Matlab (available from http://pivlab.blogspot.com/).

A total of 999 new image pairs were generated from the imported TIFF files (i.e. 1st image from the 1st image pair with the 1st image of the 2nd image pair, 1st image from the 2nd pair with the 1st image of the 3rd pair, etc.). Images were pre-processed in PIVlab using the default settings to maximise contrast between the particles (or larvae) and the background (contrast-limited adaptive histogram equalisation window size: 20 pixels; high-pass filter size: 15 pixels). Particles and larvae were white and the background nearly black. To generate the vector map, each image was divided into square regions, termed interrogation areas. PIVlab then estimated the probable shift of the particle(s) in a particular interrogation area, from the first image of an image pair to the second image in the same area, using cross-correlation between interrogation areas. Vector maps were generated using a $48 \times 48$ pixel inter- 
rogation area with a 24-pixel step (the spacing between the centres of the interrogation areas in both the $x$ and $y$ directions). A Gaussian 3-point estimator (also the default setting in PIVlab) was used to determine the sub-pixel displacement from the crosscorrelation between subsequent interrogation areas (see Westerweel 1997). To convert the displacements from units of pixels to $\mathrm{m} \mathrm{s}^{-1}$, all $u$ and $v$ component vectors were multiplied by $2.2 \times 10^{-4}$ for both the low and high turbulence with $1 \mathrm{~s}$ between image pairs, and by $4.4 \times 10^{-4}$ for high turbulence with $0.5 \mathrm{~s}$ intervals (based on calibration images analysed in PIVlab). Once all the velocity vector maps for a trial had been generated, outlier velocities were removed in 2 ways, as detailed in the following subsections.

\section{Quantification of turbulence}

For the calculation of the rate of dissipation of turbulent kinetic energy $(\varepsilon)$ based on the particle data, outliers were removed in several steps. First, for each trial, a histogram of the distribution of velocity magnitudes from the 999 vector maps were plotted and fit with a combination of a Gaussian curve (the main velocity distribution) and a triangle at higher velocities (the 'edge effect' velocity distribution). All the parameters to fit the triangular distribution, except relative height (i.e. the centre, width and skewness of the distribution), were based on the lowturbulence level, because these were best resolved and remained relatively constant among trials. For each individual vector map, any vector magnitudes beyond the Gaussian distribution were replaced with a vector calculated from the mean of the adjacent velocities. Next, 3 iterations of a spatial filter were applied. This filter compared the velocity magnitude and direction to their means over a $5 \times 5$ pixel area. Any velocities that showed magnitudes $>150 \%$ or $<67 \%$ of the mean or deviated from the mean direction by more than $\pm 45^{\circ}$, were replaced by these local means.

After outlier removal, the turbulent horizontal velocity $\left(u^{\prime}\right)$ was calculated for each velocity vector map as the RMS of the spatially pooled residual horizontal velocities (i.e. the RMS of each $u$-component in the vector map minus the mean $u$ ). To estimate the integral length scale $\left(L_{11}\right)$, an autocorrelation was performed for each $y$-position in a velocity vector map. $L_{11}$ was estimated by: (1) integrating the autocorrelation function for all positive lags, and (2) averaging the $L_{11}$ for each $y$-position to estimate mean $L_{11}$ and its standard deviation. Next, $\varepsilon$ was iteratively cal- culated for each velocity vector map using the scaling method (as discussed in de Jong et al. 2009):

$$
\varepsilon=\frac{A \cdot u^{\prime 3}}{L_{11}}
$$

with the constant of proportionality, $A$, adjusted iteratively using Burattini et al. (2005, their Fig. 3). The mean $\varepsilon$ for each turbulence level was calculated by averaging the $\varepsilon$ estimated from each vector map in the 4 or 7 trials for the low- and high-turbulence levels, respectively.

\section{Calculation of larval and particle vectors}

For data analyses comparing larval displacement to that of passive particles, a standard deviation (SD) filter was applied to the original, unfiltered vector maps of each trial. Vectors were removed if either the $u$ or $v$ component was $>2 \mathrm{SD}$ of the mean $u$ or $v$ of the entire vector map. Next, a local median filter was used. Vectors were removed if their velocity deviated $>2$ times from the local median velocity fluctuation (the median absolute difference between the velocities in a $5 \times 5$ pixel area surrounding the point and their median) plus an error allowance of $2.2 \times 10^{-5} \mathrm{~m}$ $\mathrm{s}^{-1}$ (see Westerweel \& Scarano 2005). The missing vectors were replaced by interpolation, and the resulting filtered $u$ and $v$ velocity components were used for each image. This method of outlier removal was used for the passive particles and larvae instead of the process outlined for the quantification of turbulence because the histogram of velocity magnitudes of larvae differed in shape from those of the particles.

\section{Effects of turbulence on larval swimming}

We compared the direction of displacement of the larvae with that of passive particles under each level of turbulence. For each vector map, a mean vector was generated in Matlab, and the $u$ (horizontal) and $v$ (vertical) vector components extracted, producing 999 vectors for each trial. To calculate the direction of movement, the arctangent of the $u$-component was divided by the $V$-component for each mean vector $\left(0^{\circ}\right.$ pointed towards the surface of the tank, with angle increasing clockwise). The 3 repeated trials of 999 mean vectors for particles were pooled to: (1) more accurately represent the highly skewed distribution of turbulent velocities at a particular grid speed; and (2) average the 
time-varying secondary flows present, particularly at the high-turbulence level. For the larvae, direction was calculated separately for each batch and repeated trial within a level of turbulence. For larvae in no flow, the $u$ and $v$ vector components of larval displacement were used to calculate a direction of movement in the same manner as for larvae in turbulence $(\mathrm{n}=105,55$ and 81 for each trial, respectively). The 3 replicates of larvae in no flow were pooled to: (1) maximise $n_{\text {; }}$ and (2) make the data comparable to that of the pooled trials for particles.

We used 2-way log-linear models for each batch and trial at each level of turbulence to examine: (1) the independence of particle type (larvae vs. passive particle) and angle of displacement; and (2) the independence of flow condition (larvae in no flow vs. larvae in turbulence) and angle of displacement. For this analysis, we used $60^{\circ}$ bins, with the first bin ranging from $330^{\circ}$ to $30^{\circ}$ (i.e. centred at $0^{\circ}$ ), representing movement toward the water surface. Initial analyses indicated that models of greater complexity had significant interactions $\left(G>>G_{\text {crit }}\right.$ p $\left.<0.001\right)$. Since log-linear tests are sensitive to the number of observations, and given that we had 999 observations per trial, we standardised the frequency of angles by converting the absolute frequency of occurrence to a percentage, and used $\alpha=0.01$. The analyses by log-linear models were done using SPSS for Windows.

In addition, for each batch and trial of larvae in turbulence, for passive particles and for larvae in no flow, directionality was displayed. We: (1) calculated the mean direction of displacement and $95 \%$ confidence intervals (CI); and (2) generated box plots of the vertical components of velocity for each batch and trial of larvae and passive particles at each level of turbulence and for larvae in no flow. We conducted pairwise comparisons in mean directions of movement, and median velocity and range: (1) between batches for each trial and turbulence level; (2) between trials for each batch and turbulence

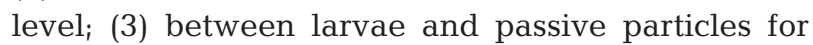
each batch, trial and turbulence level; and (4) between larvae in no flow and larvae in turbulence for each batch, trial and turbulence level. These comparisons were made to determine whether there was an effect of trial or batch on larval movement, as well as whether larvae in turbulence were moving differently from the passive particles in turbulence or the larvae in no flow. In any comparison, if the $95 \%$ CI of the 2 means overlapped, we concluded that there was no significant difference in mean direction.

\section{RESULTS}

\section{Turbulent dissipation rate}

For the low-turbulence setting, $\varepsilon$ was $9 \times 10^{-9} \pm 7$ $\times 10^{-9} \mathrm{~W} \mathrm{~kg}^{-1}$ (mean $\pm \mathrm{SD}$ ), with a median of $5 \times$ $10^{-9} \mathrm{~W} \mathrm{~kg}^{-1}$. The mean was $4 \times 10^{-4} \pm 3 \times 10^{-5} \mathrm{~m}$ $\mathrm{s}^{-1}$. For the high-turbulence setting, $\varepsilon$ was $4 \times 10^{-7}$ $\pm 1 \times 10^{-7} \mathrm{~W} \mathrm{~kg}^{-1}$, with a median $\varepsilon$ of $3 \times 10^{-7} \mathrm{~W}$ $\mathrm{kg}^{-1}$ and a mean $u$ of $1 \times 10^{-3} \pm 5 \times 10^{-5} \mathrm{~m} \mathrm{~s}^{-1}$. Turbulence in the tank as a whole was nearly isotropic (Fig. A1 in Appendix 1). There appeared to be secondary flows in the tank in high turbulence that varied over time, as shown by the change in direction of particle displacement among trials (Fig. A2 in Appendix 1). These secondary flows were also evident in the high-turbulence particle trials collected at half-second intervals (A. Roy unpubl. data).

\section{Effects of turbulence on larval displacement}

\section{Angle of displacement}

Larvae of Strongylocentrotus droebachiensis in turbulence displayed directionality in their movement that varied between turbulence levels, trials and batches. In low turbulence, larvae tended to move towards the water surface, similarly to larvae in no

Table 1. Strongylocentrotus droebachiensis. Percentage of larvae showing 1 of 2 calculated directions of displacement (up, i.e. towards water surface: $285-75^{\circ}$, centred at $0^{\circ}$; down, i.e. towards bottom of the tank: $105-255^{\circ}$, centred at $180^{\circ}$ ) for each batch (B) and trial (T) and level of turbulence (low or high) for larvae and passive particles, and for larvae in no flow. To avoid ambiguous results, we did not include displacements within the intervals $75-105^{\circ}$ (centred at $90^{\circ}$ ) or $255-285^{\circ}$ (centred at $270^{\circ}$ ); consequently, percentages below do not add to 100 for a particular treatment combination

\begin{tabular}{|lccrr|}
\hline & \multicolumn{2}{c}{ Low turbulence } & \multicolumn{2}{c|}{ High turbulence } \\
& Up & Down & Up & Down \\
\hline Larvae (\%) & & & & \\
B1, T1 & 78 & 22 & 0 & 100 \\
B1, T2 & 56 & 43 & 0 & 98 \\
B2, T1 & 57 & 32 & 72 & 16 \\
B2, T2 & 66 & 28 & 76 & 14 \\
No flow & 79 & 14 & 79 & 14 \\
Particles (\%) & & & & \\
T1 & 60 & 30 & 64 & 34 \\
T2 & 43 & 42 & 99 & 0 \\
T3 & 41 & 35 & 85 & 2 \\
\hline
\end{tabular}


flow (Fig. 2, Table 1). In high turbulence, larval movement was along a particular axis, although in opposite directions for the 2 batches (Fig. 3, Table 1). At both turbulence levels, passive particles moved in more directions than larvae (Figs. $2 \& 3$, Table 1). The distribution of directions of displacement differed significantly between larvae and passive particles for both turbulence levels, as well as between larvae in turbulence and no flow (Table 2). In low turbulence, mean angle of displacement for Batch 1 was similar to that of larvae in no flow, and different from that of passive particles during both trials (Fig. 4). For Batch 2 , mean angle of displacement was different between trials, becoming more similar to larvae in no flow over time (Fig. 4). For larvae in high turbulence, mean angle of displacement was similar between trials within a batch, differed significantly between

\section{Low turbulence}
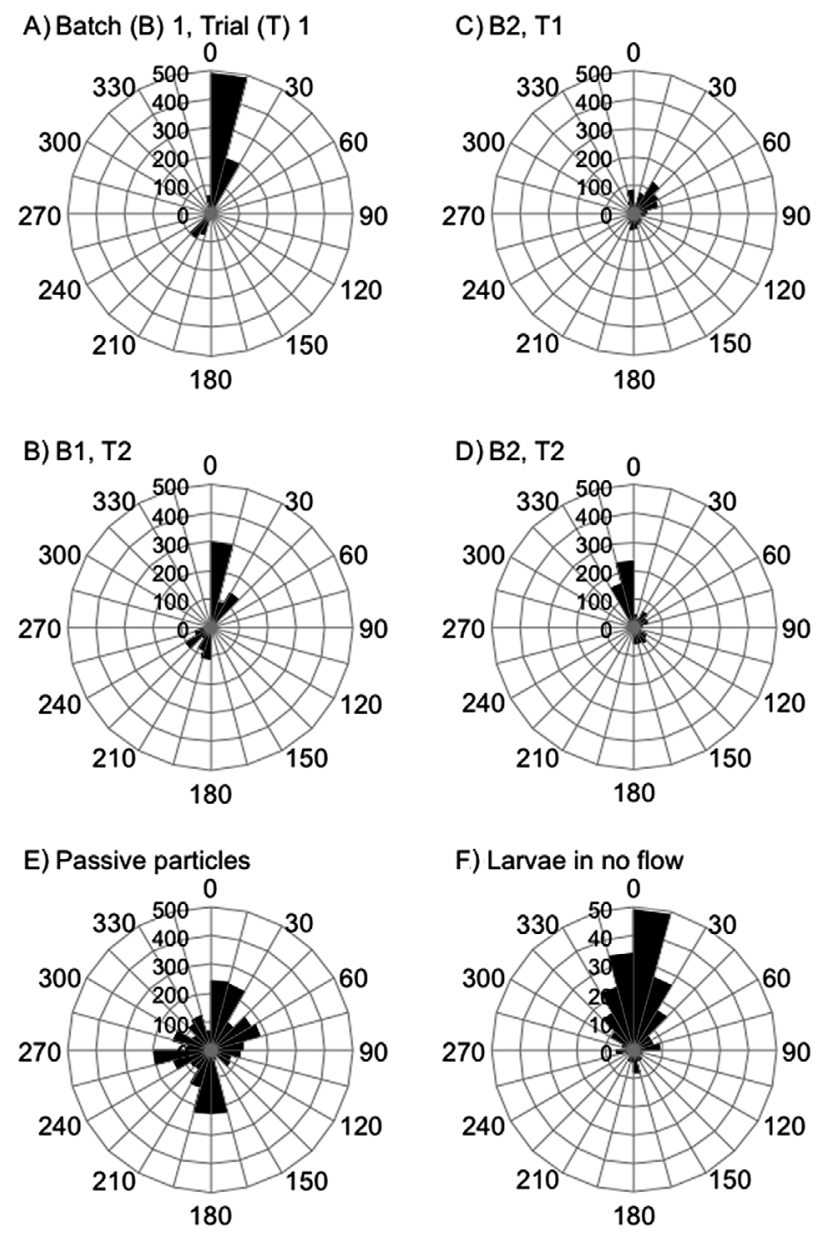

Fig. 2. Strongylocentrotus droebachiensis. Low turbulence: frequency distributions of angle of displacement for larvae of (A) Batch 1, Trial 1, (B) Batch 1, Trial 2, (C) Batch 2, Trial 1, and (D) Batch 2, Trial 2; (E) passive particles, and (F) larvae in no flow
Table 2. Strongylocentrotus droebachiensis. Log-linear models of the independence between angular displacement of larvae in turbulence and either passive particles (P) or larvae in no flow $(\mathrm{N})$. Because the more complex models indicated significant multi-way interactions, simpler models were run for each individual measure. B: Batch, T: Trial. *Significant difference $(\alpha=0.01)$ in frequency distributions

\begin{tabular}{|lcccccc|}
\hline \multirow{2}{*}{ Comparison } & \multicolumn{3}{c}{ Low turbulence } & \multicolumn{3}{c|}{ High turbulence } \\
& $G$ & $\mathrm{df}$ & $\mathrm{p}$ & $\mathrm{G}$ & $\mathrm{df}$ & $\mathrm{p}$ \\
\hline B1, T1 vs. P & 73.8 & 5 & $<0.001^{*}$ & 258 & 5 & $<0.001^{*}$ \\
B1, T2 vs. P & 28.2 & 5 & $<0.001^{*}$ & 258 & 5 & $<0.001^{*}$ \\
B2, T1 vs. P & 10.4 & 5 & $<0.001^{*}$ & 41.9 & 5 & $<0.001^{*}$ \\
B2, T2 vs. P & 29.7 & 5 & 0.013 & 36.4 & 5 & $<0.001^{*}$ \\
B1, T1 vs. N & 34.4 & 5 & $<0.001^{*}$ & 212 & 5 & $<0.001^{*}$ \\
B1, T2 vs. N & 36.6 & 5 & $<0.001^{*}$ & 234 & 5 & $<0.001^{*}$ \\
B2, T1 vs. N & 32.6 & 5 & 0.065 & 59.0 & 5 & $<0.001^{*}$ \\
B2, T2 vs. N & 14.4 & 5 & $<0.001^{*}$ & 58.2 & 5 & $<0.001^{*}$ \\
\hline
\end{tabular}

\section{High tubulence}
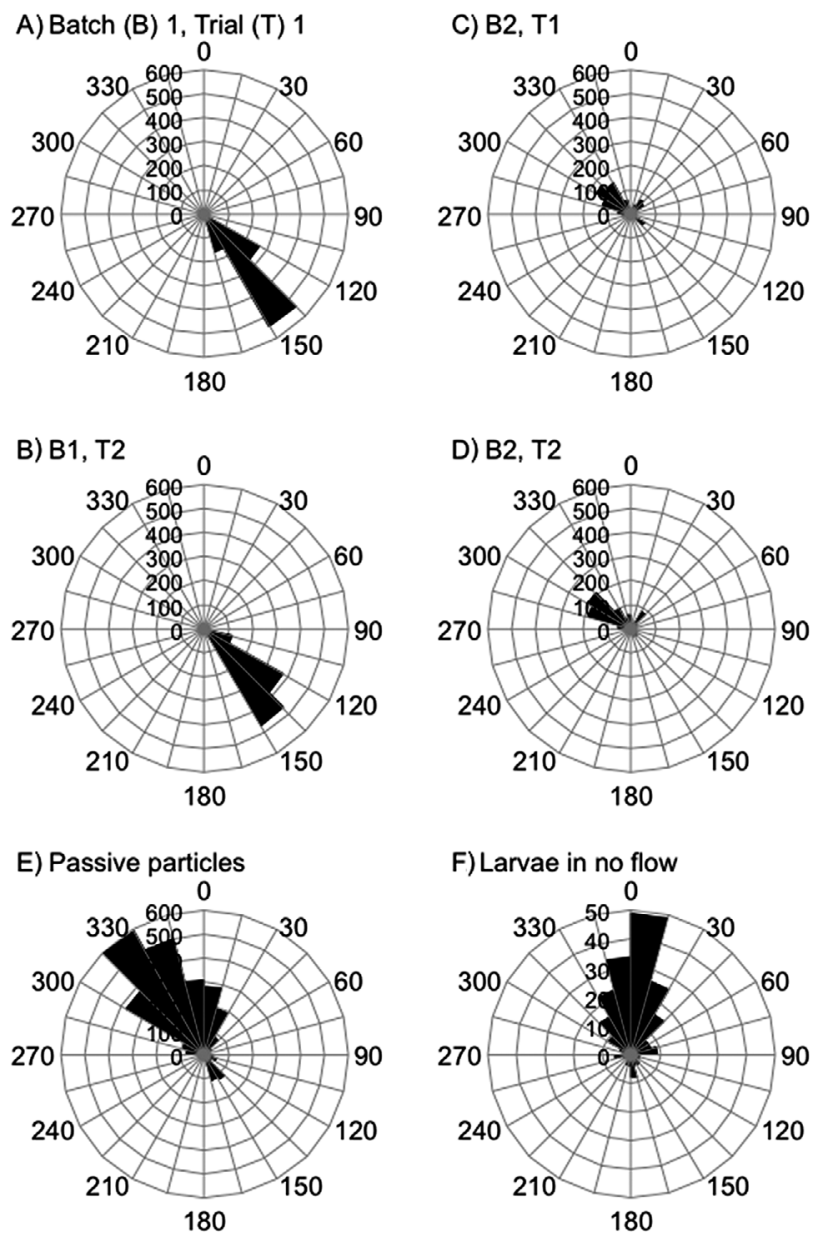

Fig. 3. Strongylocentrotus droebachiensis. High turbulence: frequency distributions of angle of displacement for larvae. Lettering as in Fig. 2 


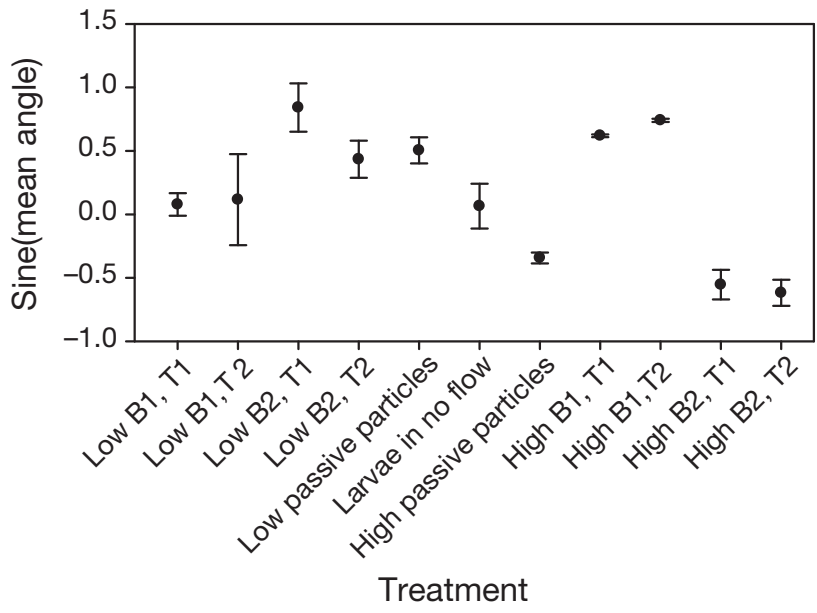

Fig. 4. Strongylocentrotus droebachiensis. Sine-transformed angle of displacement (radians, mean $\pm 95 \% \mathrm{CI}$ ) for each batch (B), trial (T) and level of turbulence (low or high) for larvae, passive particles, and larvae in no flow

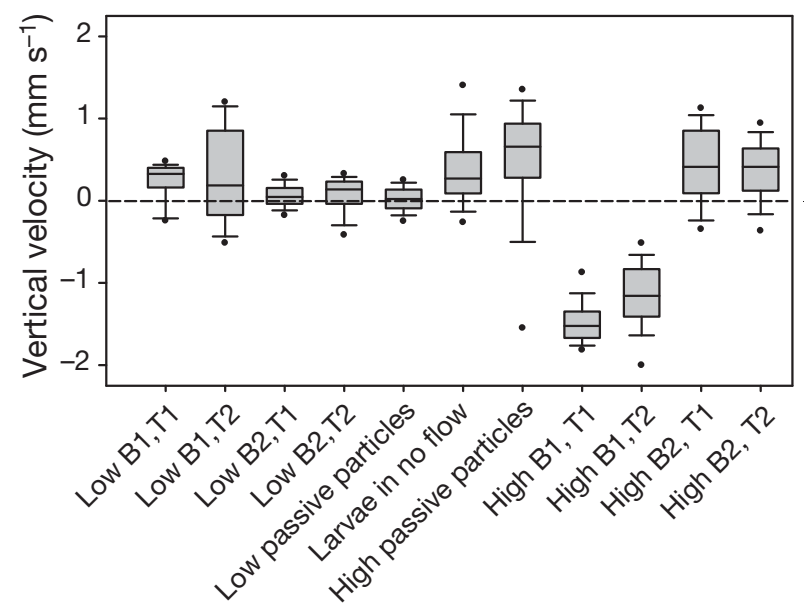

Treatment

Fig. 5. Strongylocentrotus droebachiensis. Box plots of vertical velocity for each batch (B), trial (T) and level of turbulence (low or high) for larvae, passive particles, and larvae in no flow

batches, and, for both batches, differed from those of both passive particles and larvae in no flow (Fig. 4).

\section{Vertical velocity}

At both turbulence levels, larvae and passive particles, as well as the larvae in no flow, had slightly positive median vertical velocities (towards the surface of the water), except for Batch 1 high turbulence (Fig. 5). The median vertical velocity for larvae in low turbulence tended to be greater than that of the passive particles, but lower than larvae in no flow, whereas in high turbulence, passive particles had a greater vertical velocity than the larvae (Fig. 5). The range of vertical velocities was greater for larvae in low turbulence and in no flow than passive particles, whereas in high turbulence, larvae and passive particles had a similar range in vertical velocities (Fig. 5). Unlike larvae in low turbulence, there were pronounced batch effects in vertical velocity for larvae in high turbulence (Fig. 5). The range of vertical velocities did not overlap between batches (Fig. 5).

\section{DISCUSSION}

In general, larvae of Strongylocentrotus droebachiensis in low turbulence $\left(10^{-9}\right.$ to $\left.10^{-8} \mathrm{~W} \mathrm{~kg}^{-1}\right)$ had a different direction of displacement than passive particles. Larvae in low turbulence and in no flow tended to move towards the surface of the water, particularly as larvae became habituated, whereas the particles exhibited a greater range of directions of displacement. Larvae also displayed a much greater range in vertical velocities than the passive particles, and a similar range to larvae in no flow. We suggest that at $\varepsilon$ levels of $10^{-9}$ to $10^{-8} \mathrm{~W} \mathrm{~kg}^{-1}$, larvae of $S$. droebachiensis are only marginally affected by turbulence. Spat of the scallop Placopecten magellanicus, also a weak swimmer, were found to be able to regulate their depth in turbulence up to $10^{-8} \mathrm{~W}$ $\mathrm{kg}^{-1}$, and thus were also minimally influenced by the flow regime at these levels (Pearce et al. 1998).

In contrast, larvae of Strongylocentrotus droebachiensis exposed to $\varepsilon$ values on the order of $10^{-7} \mathrm{~W}$ $\mathrm{kg}^{-1}$ did not swim towards the surface and appeared to be unable to maintain their orientation in this level of turbulence. There was high variation in the direction of displacement of passive particles at the highturbulence level, suggesting that directionally variable secondary flows are typical of the experimental tank (A. Roy \& T. Ross unpubl. data). While the presence of these secondary flows prevents us from comparing the displacement of larvae in high turbulence to those of the passive particles, the low variance in larval displacement within a batch suggests that the larvae were carried in the same secondary circulation for the duration of their exposure. Furthermore, while the secondary flow patterns within the turbulence tank remain unresolved, it is apparent that at high $\varepsilon$ values (e.g. $10^{-7} \mathrm{~W} \mathrm{~kg}^{-1}$ ), larval $S$. droebachiensis are unable to maintain their orientation and swim towards the surface of the water, as is consistently demonstrated by larvae in calmer conditions. 
Larvae of similar swimming ability, but different morphologies, respond differently to turbulence. Rather than being reoriented, spat of Placopecten magellanicus were unable to maintain their vertical position in the water column at turbulence levels of $10^{-7} \mathrm{~W} \mathrm{~kg}^{-1}$, and became randomly mixed (Pearce et al. 1998). In contrast, competent larvae of Ilyanassa obsoleta were not affected by turbulence until exposed to a threshold level of $10^{-5} \mathrm{~W} \mathrm{~kg}^{-1}$, when they ceased swimming and sank quickly to the bottom, possibly using turbulence as a cue to settle (Fuchs et al. 2004). Other competent gastropods sink in calm waters, but swim upwards at $\varepsilon$ of $10^{-5} \mathrm{~W} \mathrm{~kg}^{-1}$ (Fuchs et al. 2004).

There was some evidence of habituation under low turbulence, since direction of displacement of larvae in turbulence became more similar to that of larvae in no flow over time, particularly for Batch 2, which initially behaved similarly to passive particles. Habituation has been noted for several copepod species, with an initial increase in the number of escape reactions lasting $\sim 3$ to $5 \mathrm{~min}$ following the initiation of turbulence, followed by a period of foraging (Costello et al. 1990, Seuront et al. 2004). Typically, these responses by copepods were triggered at $\varepsilon$ values of $10^{-7}$ to $10^{-5} \mathrm{~W} \mathrm{~kg}^{-1}$ (Costello et al. 1990, Seuront et al. 2004). As larvae of Strongylocentrotus droebachiensis are weaker swimmers $\left(\sim 0.1 \mathrm{~mm} \mathrm{~s}^{-1}\right)$ than copepods (1 to $10 \mathrm{~mm} \mathrm{~s}^{-1}$; Yamazaki \& Squires 1996), habituation to turbulence for them would likely occur at lower values of $\varepsilon$. In contrast to larvae in low turbulence, larvae in high turbulence did not display evidence of habituation, suggesting that in turbulence $>10^{-7} \mathrm{~W}$ $\mathrm{kg}^{-1}$, larvae of $S$. droebachiensis are not able to swim independently of the turbulent flow.

Larval response to high turbulence varied among batches, and direction of displacement and vertical velocity was more similar between trials of the same batch than between batches at the same trial. It is unclear why there was more consistency in behavioural response within a batch than among batches, particularly since batches represented multiple parental pairs. Echinoderm plutei are particularly susceptible to reorientation in shear flow (Metaxas et al. 2009, Clay \& Grünbaum 2010, Sameoto et al. 2010), and responses to shear forces are stagedependent and vary both with morphology and flow regime (Clay \& Grünbaum 2010, 2011). Although these larval swimming abilities were studied under shear flow, larval swimming in turbulence is also likely to be affected by morphology. Four-arm plutei of Strongylocentrotus droebachiensis are unable to regulate their vertical position at shears $>2 \mathrm{~s}^{-1}$, which are found in regions with $\varepsilon$ of $\sim 10^{-5} \mathrm{~W} \mathrm{~kg}^{-1}$ (Sameoto et al. 2010). Alternatively, variations in the secondary flows present in the tank at the high-turbulence level may have affected the displacement of the larvae, causing larvae within the same batch to be more similar than those among batches.

The levels of turbulent dissipation rates in our experimental treatments correspond to values in habitats that larval sea urchins will encounter during their dispersal. For example, $\varepsilon$ of $10^{-8} \mathrm{~W} \mathrm{~kg}^{-1}$ have been measured in bays below the thermocline, at intermediate depths $(\geq 2 \mathrm{~m}$ to several $\mathrm{m}$ above the seafloor; Goodman \& Wang 2009) and in the mixed layer of the continental shelf (Incze et al. 2001), and $\varepsilon$ values similar to the high-turbulence treatment have been measured near the surface and the seabed in shallow bays (Goodman \& Wang 2009) and near the pycnocline on the continental shelf (Incze et al. 2001). Since larvae of Strongylocentrotus droebachiensis inhabit these types of environments, their dispersal will likely be affected by turbulent flow conditions. Although it is currently unknown how far offshore 4-arm plutei of $S$. droebachiensis disperse, larvae of Paracentrotus lividus, a Mediterranean sea urchin, have been found up to $20 \mathrm{~km}$ offshore, although typically they are found $<10 \mathrm{~km}$ offshore (Pedrotti \& Fenaux 1992). In calm conditions with low turbulence, larvae of $S$. droebachiensis appear to be able to swim towards the surface of the water, which may promote advection away from the parental habitat. Conversely, in more turbulent conditions, larvae are likely to be reoriented away from the surface of the water column, resulting in wider dispersal ranges as larvae enter water layers with different horizontal velocities.

To date, there have been limited studies investigating the effects of turbulence on the swimming of larval invertebrates, and these have focused on competent larvae. Our results suggest that 4-arm plutei of Strongylocentrotus droebachiensis are able to swim towards the surface of the water, mostly as in no-flow conditions, in turbulence as great as $10^{-8}$ $\mathrm{W} \mathrm{kg}{ }^{-1}$, and that this behaviour becomes more pronounced with habituation. At turbulence levels of $10^{-7} \mathrm{~W} \mathrm{~kg}^{-1}$, larvae do not behave as larvae in noflow conditions, suggesting that they are carried within the secondary flows as passive particles. Larvae in near-shore coastal embayments or the surface layer of the continental shelf would experience turbulence similar to levels tested in the present study, and thus this change in behaviour could affect larval dispersal away from, or towards, parental habitats. 
Acknowledgements. We thank J. Lindley for collecting adult sea urchins, and J. Eddington and Dalhousie University's Aquatron for assistance during larval rearing and experiments. Comments by 3 anonymous reviewers helped improve the manuscript. Funding for this study was provided by a Natural Sciences and Engineering Research Council of Canada (NSERC) Discovery Grant to A.M. and T.R., and a Canadian Foundation for Innovation (CFI) New Opportunities Grant to A.M.

\section{LITERATURE CITED}

Batty RS (1984) Development of swimming movements and musculature of larval herring (Clupea harengus). J Exp Biol 110:217-229

Burattini P, Lavoie P, Antonia RA (2005) On the normalized turbulent energy dissipation rate. Phys Fluids 17:098103

Chia FS, Buckland-Nicks J, Young CM (1984) Locomotion of marine invertebrate larvae: a review. Can J Zool 62: 1205-1222

Clay TW, Grünbaum D (2010) Morphology-flow interactions lead to stage selective vertical transport of larval sand dollars in shear flow. J Exp Biol 213:1281-1292

Clay TW, Grünbaum D (2011) Swimming performance as a constraint on larval morphology in plutei. Mar Ecol Prog Ser 423:185-196

> Costello JH, Strickler JR, Marrasé C, Trager G, Zeller R, Freise AJ (1990) Grazing in a turbulent environment: behavioural response of a calanoid copepod, Centropages hamatus. Proc Natl Acad Sci USA 87: 1648-1652

de Jong J, Cao L, Woodward SH, Salazar JPLC, Collins LR, Meng H (2009) Dissipation rate estimation from PIV in zero-mean isotropic turbulence. Exp Fluids 46: 499-515

> Dillon TM, Caldwell DR (1980) The Batchelor Spectrum and dissipation in the upper ocean. J Geophys Res Oceans 85:1910-1916

Fuchs HL, Mullineaux LS, Solow AR (2004) Sinking behaviour of gastropod larvae (Ilyanassa obsoleta) in turbulence. Limnol Oceanogr 49:1937-1948

> Fuchs HL, Solow AR, Mullineaux LS (2010) Larval response to turbulence and temperature in a tidal inlet: habitat selection by dispersing gastropods? J Mar Res 68: 153-188

- George R, Flick RE, Guza RT (1994) Observations of turbulence in the surf zone. J Geophys Res Oceans 99:801-810

Goodman L, Wang Z (2009) Turbulence observations in the northern bight of Monterey Bay from a small AUV. J Mar Syst 77:441-458

Gross TF, Nowell ARM (1985) Spectral scaling in a tidal boundary layer. J Phys Oceanogr 15:496-508

Haury LR, Yamazaki H, Itsweire EC (1990) Effects of turbulent shear flow on zooplankton distribution. Deep-Sea Res A 37:447-461

Hopfinger EJ, Toly JA (1976) Spatially decaying turbulence and its relation to mixing across density interfaces. J Fluid Mech 78:155-175

Incze LS, Hebert D, Wolff N, Oakey N, Dye D (2001) Changes in copepod distributions associated with increased turbulence from wind stress. Mar Ecol Prog Ser 213:229-240

> Luckenbach MW, Orth RJ (1992) Swimming velocities and behaviour of blue crab (Callinectes sapidus Rathburn) megalope in still and flowing water. Estuaries 15: 186-192

Lueck RG, Crawford WR, Osborn TR (1983) Turbulent dissipation over the continental slope off Vancouver Island. J Phys Oceanogr 13:1809-1818

Maar M, Visser AW, Nielsen TG, Stips A, Saito H (2006) Turbulence and feeding behaviour affect the vertical distributions of Oithona similis and Microsetella norwegica. Mar Ecol Prog Ser 313:157-172

Metaxas A (2001) Behaviour in flow: perspectives on the distribution and dispersion of meroplanktonic larvae in the water column. Can J Fish Aquat Sci 58:86-98

> Metaxas A, Burdett-Coutts V (2006) Response of invertebrate larvae to the presence of the ctenophore Bolinopsis infudibulum, a potential predator. J Exp Mar Biol Ecol 334:187-195

Metaxas A, Young CM (1998) Responses of echinoid larvae to food patches of different algal densities. Mar Biol 130: 433-445

> Metaxas A, Mullineaux LS, Sisson J (2009) Distribution of echinoderm larvae relative to the halocline of a salt wedge. Mar Ecol Prog Ser 377:157-168

$>$ Oakey SN, Elliott JA (1982) Dissipation within the surface mixed layer. J Phys Oceanogr 12:171-185

> Pearce CM, Gallager SM, Manuel JL, Manning DA, O'Dor RK, Bourget E (1998) Effect of thermoclines and turbulence on depth of larval settlement and spat recruitment of the giant scallop Placopecten magellanicus in $9.5 \mathrm{~m}$ deep laboratory mesocosms. Mar Ecol Prog Ser 165: 195-215

> Pedrotti ML, Fenaux L (1992) Dispersal of echinoderm larvae in a geographical area marked by upwelling (Ligurian Sea, NW Mediterranean). Mar Ecol Prog Ser 86: 217-227

> Pernet F, Tremblay R, Bourget E (2003) Settlement success, spatial pattern and behavior of mussel larvae Mytilus spp. in experimental 'downwelling' systems of varying velocity and turbulence. Mar Ecol Prog Ser 260:125-140

> Pringle JM (2007) Turbulence avoidence and the wind-driven transport of plankton in the surface Ekman layer. Cont Shelf Res 27:670-678

Roy A, Metaxas A, Daigle RM (2012) Changes in vertical distribution and aggregative behaviour in response to population density for larval sea urchins (Strongylocentrotus droebachiensis) and sea stars (Asterias rubens). Mar Ecol 33:194-204

Saiz E, Alcaraz M (1991) Effects of small-scale turbulence on development time and growth of Arcatia grani (Copepoda: Calanoida). J Plankton Res 13:873-883

Saiz E, Alcaraz M (1992) Free-swimming behaviour of Arcatia clausi (Copepoda: Calanoida) under turbulent water movement. Mar Ecol Prog Ser 80:229-236

Sameoto JA, Ross T, Metaxas A (2010) The effect of flow on larval vertical distribution of the sea urchin, Strongylocentrotus droebachiensis. J Exp Mar Biol Ecol 383: 156-163

Seuront L, Yamazaki H, Souissi S (2004) Hydrodynamic disturbance and zooplankton swimming behaviour. Zool Stud 43:376-387

Strathmann RR, Hughes TP, Kuris AM, Lindeman KC, Morgan SG, Pandolfi JM, Warner RR (2002) Evolution of local recruitment and its consequences for marine populations. Bull Mar Sci 70:377-396

Welch JM, Forward RB Jr (2001) Flood tide transport of blue 
crab, Callinectes sapidus, postlarvae: behavioural responses to salinity and turbulence. Mar Biol 139: 911-918

Welch JM, Forward RM Jr, Howd PA (1999) Behavioural responses of blue crab Callinectes sapidus postlarvae to turbulence: implications for selective tidal stream transport. Mar Ecol Prog Ser 179:135-143

Westerweel J (1997) Fundamentals of digital particle image velocimetry. Meas Sci Technol 8:1379-1392
Westerweel J, Scarano F (2005) Universal outlier detection for PIV data. Exp Fluids 39:1096-1100

Yamazaki H, Squires KD (1996) Comparison of oceanic turbulence and copepod swimming. Mar Ecol Prog Ser 144: 299-301

Young CM (1995) Behaviour and locomotion during the dispersal phase of larval life. In: McEdward LR (ed) Ecology of marine invertebrate larvae. CRC Press, Boca Raton FL, p 249-277

Appendix 1. Turbulent dissipation rate: additional data

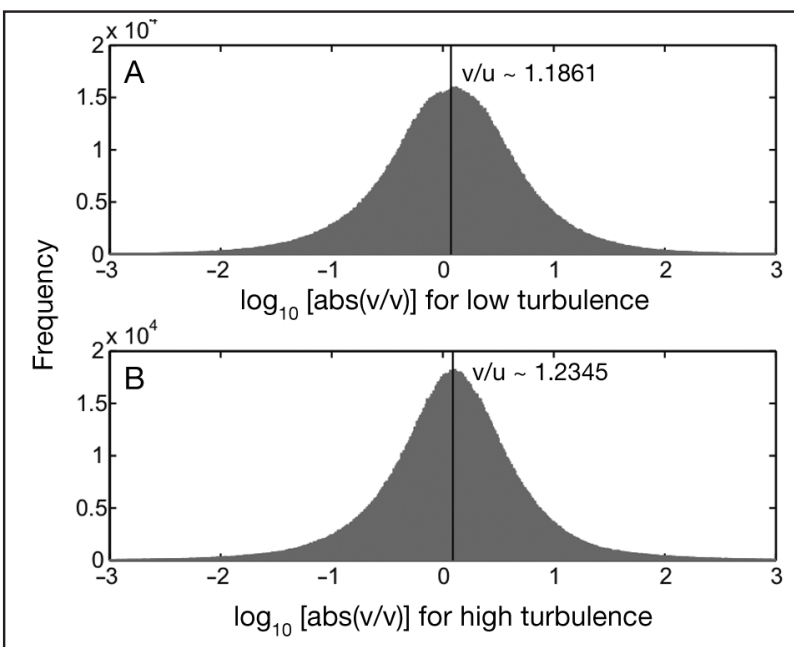

Fig. A1. Movement of passive particles. Degree of isotropy at (A) low and (B) high turbulence levels, represented by the frequency distributions of the ratio of the vertical to horizontal velocity components $(v / u$; as in Hopfinger \& Toly 1976, their Fig. 7)

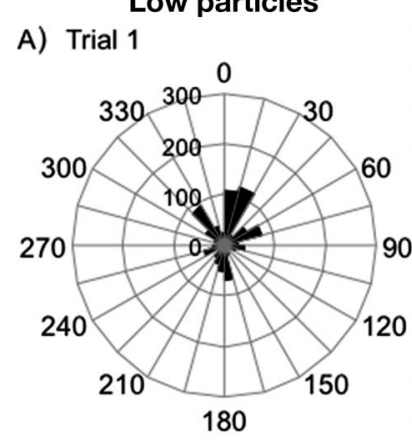

B) Trial 2

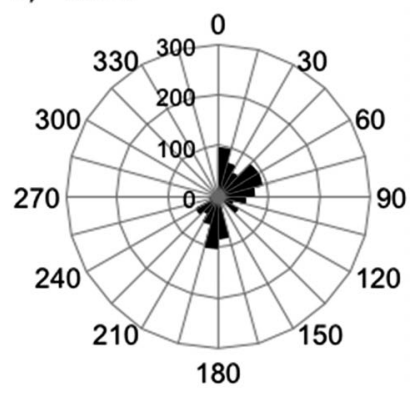

C) Trial 3

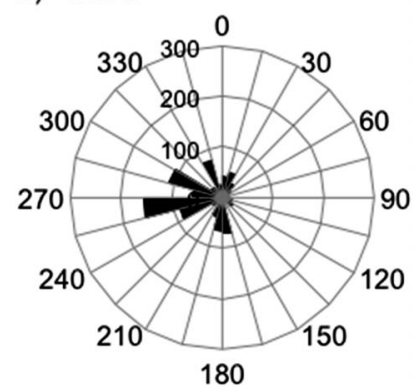

\section{High particles}

D) Trial 1

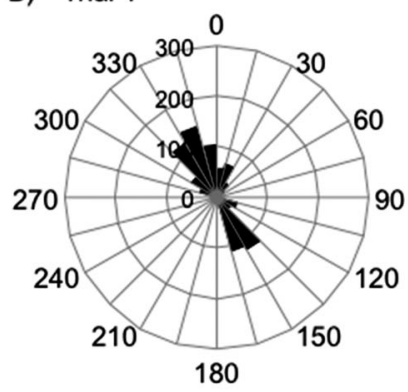

E) Trial 2

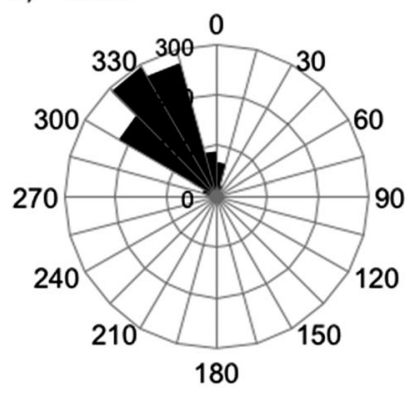

F) Trial 3

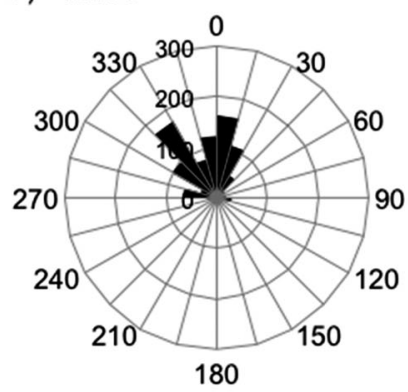

Fig. A2. Passive particles: frequency distributions of angle of displacement for low turbulence in Trials (A) 1, (B) 2 and (C) 3, and high turbulence in Trials (D) 1, (E) 2 and (F) 3

Editorial responsibility: James McClintock, Birmingham, Alabama, USA
Submitted: August 26, 2011; Accepted: February 2, 2012

Proofs received from author(s): May 1, 2012 